\title{
ANALISIS KEBUTUHAN JALUR PEDESTRIAN DI KAWASAN GAJAHMADA PONTIANAK
}

\begin{abstract}
Eva Zulianna ${ }^{1)}$
Abstrak

Kebutuhan pedestrian di kota-kota besar menjadi salah satu ruang gerak publik yang cukup menjadi perhatian saat ini. Oleh karena itu, Pemerintah Kota Pontianak mulai merencanakan kebutuhan ruang untuk pejalan kaki di Kota Pontianak, salah satunya di Jalan Gajahmada. Jalan Gajahmada memiliki karakteristik unik dibandingkan jalan protokol lainnya, karena Jalan Gajahmada telah ditetapkan menjadi Kawasan Perdagangan dan Jasa berdasarkan Rencana Tata Ruang Wilayah Kota Pontianak Tahun 2013 - 2033. Penelitian ini diawali dengan obeservasi lapangan untuk menentukan zonasi sampel penelitian. Observasi dilakukan dengan cara pengamatan langsung ke lapangan tempat lokasi dilakukannya penelitian. Merekam dengan cara memotret aktfivitas yang terjadi di pedestrian dan menggambarkan kepadatan pejalan kaki yang ada. Menghitung volume pejalan kaki yang melintasi titik-titik pengamatan di lokasi penelitian. Perhitungan untuk menrencanakan lebar trotoar efektif didapatkan yaitu 5 meter dan analisis tingkat pelayanan fasilitas pejalan kaki, Jalan Gajahmada dapat direncanakan dengan tingkat pelayanan standar A atau LOS A. Hasil dari responden, bahwa kebutuhan fasilitas mendukung moda transportasi menuju jalur pedestrian yaitu membutuhkan gedung parkir.
\end{abstract}

Kata-kata kunci: pedestrian, pejalan kaki

\section{PENDAHULUAN}

Dalam pertumbuhan dan perkembangan kawasanya ini kemudian muncul beberapa isu-isu permasalahan baik dalam konteks skala bangunan dan lingkungan. Beberapa masalah tersebut antara lain sistem parkir dan sirkulasi kendaraan yang telah membentuk kualitas lingkungan yang sangat rendah, tidak ada jalur pejalan kaki yang jelas, tata letak dan sistem reklame/signage yang tidak teratur, bentuk dan masa bangunan yang sudah menggeser karakter dan budaya lokal dan lain sebagainya. Disamping itu, muncul beberapa isu potensi yang ada didalam kawasan dan menjadi karakter dari jalan Gajahmada ini. Beberapa potensi tersebut yakni adanya aktifitas cafe street hampir disepanjang jalur jalan ini, kawasan Hajahmada sebagai tujuan wisata kuliner bagi masyarakat Kota Pontianak.
Aktifitas pejalan kaki menjadi sangat penting akibat pembangunan gedung parkir. Perencanaan pembangunan trotoar humanis di Gajahmada menjadi ruang terbuka pada kawasan tersebut. Secara umum penataan ruang terbuka berkaitan dengan elemen perabot taman/jalan(street furniture), dan tata hijau. Pada koridor jalan Gajahmada terlihat elemen perabot tidak adanya keseragaman baik untuk penerangan, dan kelengkapan street furniture lainnya. Tidak adanya tempat untuk rest area untuk pejalan kaki. Elemen penghijauan terdapat beberapa pohon pelindung namun perletakan dan jarak sekitar teratur.

Dari pembahasan diatas, perencanaan pembangunan trotoar humanis di Jalan Gajahmada yang 
dilakukan oleh Pemerintah Kota Pontianak, melatarbelakangi penulis untuk menganalisa karakteristik dan kebutuhan fasilitas pejalan kaki terhadap pembangunan trotoar di jalan Gajahmada Pontianak.

\section{TINJAUAN PUSTAKA}

\subsection{Refrensi Penelitian}

Lukman Wibowo (2005), telah melakukan penelitian dengan judul "Studi Tentang Kenyamanan Pejalan Kaki Terhadap Pemanfaatan Trotoar di Jalan Protokol Kota Semarang (studi Kasus Jalan MT. Haryoni Semarang". Lokasi penelitian ini pada ruas Jalan MT. Haryono Semarang. Adapun metode yang dipakai dengan menggunakan metode sampel dan teknik sampling serta menyebarkan lembar kuisioner. Dari penelitian telah diperoleh hasilnya yaitu bahwa hasil perhitungan analisis deskriptif presentase yang diperoleh memberikan keterangan bahwa dari jumlah responden sebanyak 100 pejalan kaki (dalam 4 zona pengambilan sampel populasi) adalah tergolong dalam kriteria tingkat kenyamanan yang kurang baik.

Indira Sari (2001), telah melakukan penelitian dengan judul "Analisa Pola Perjalanan Pejalan Kaki (Pedesterian) di Kawasan Pertokoan Dika dan Sekitarnya". Pada penelitian ini peneliti menggunakan metode program SPSS 7.5.. Dari penelitian ini telah didapat hasilnya yaitu, besarnya pergerakan yang terjadi antar zona dipengaruhi dengan daya tarik kawasan zona itu masingmasing. Bila suatu zona mempunyai daya tarik yang besar maka akan banyak perjalanan yang masuk pada zona tersebut. Sedangkan pembebanan pada jaringan pejalan kaki terbanyak pada ruas trotoar 14. Pada volume pedeseterian untuk hari libur meningkat. Hal ini dikarenakan pada hari libur pedestrian tidak melakukan aktivitas seperti hari kerja.

Barnabas Untung Sudianto (1997), telah melakukan penelitian dengan judul "Fasilitas Pejalan Kaki di Pusat Pertokoan (Studi Kasus di Pusat Pertokoan Salatiga)". Maksud dari penelitian ini adalah membuat permodelan kebutuhan fasilitas pejalan kaki di pisat pertokoan. Penelitian ini dilakukan di pusat pertokoan Jalan Jendral sudirman Salatiga. Pusat penelitian ini dibagi menjadi 2 zona. Setiap zona dibagi dalam 6 seksi dan diambil 2 persimpangan jalan. Data lapangan diolah dan dianalisis untuk menghasilkan model fasilitas pejalan kaki di pusat pertokoan. Model fasilitas pejalan kaki terdiri dari lebar efektif trotoar, tinggi trap refure dan luas sudut persimpangan jalan. Aplikasi model di pusat pertokoan menunjukkan hasil yang baik. Khususnya aplikasi model di pusat pertokoan. Pada aplikasi model fasilitas pejalan kaki di pusat pertokoan Salatiga menghasilkan rekomendasi setempat.

Indriastuti, Amelia Kusuma dkk (2014), telah melakukan penelitian dengan judul "Evaluasi Kinerja Ruang Pejalan Kaki di Jalan Malioboro Yogyakarta”. Penelitian ini bertujuan untuk menganalisis perencanaan uang dapat menampung kebutuhan selama 5 tahun mendatang pada area pedestrian untuk mencapai nilai Level of service (LOS) B. 


\subsection{Pedestrian}

Fungsi jalur pedestrian yang disesuaikan dengan perkembangan kota adalah sebagai fasilitas pejalan kaki, unsur keindahan kota, media interaksi sosial, sarana Istilah pedestrian juga berasal dari bahasa latin yakni, pedesterpedestris yang diartikan sebagai orang yang berjalan kaki atau pejalan kaki.

Upaya Jalan kaki merupakan bentuk sarana transportasi paling sederhana dalam melakukan kegiatan dari satu tempat menuju tempat lain. Dalam tesis, ( Widodo, Mulyadi, 2001, jalur pejalan kaki pada jalan Pandanaran) dituliskan bahwa berjalan kaki merupakan alat pergerakan internal kota, dan satusatunya alat untuk memenuhi kebutuhan interaksi tatap muka di dalam aktifitas komersial dan kultural di lingkungan kota. Berjalan kaki merupakan penghubung antara moda-moda angkutan yang tidak mungkin dikerjakan oleh moda angkutan yang lain. Dari situ jelas bahwa dengan berjalan kaki orang dapat bebas berinteraksi dengan siapapun termasuk saat melakukan transaksi dengan seorang penjual.

\section{Menurut Uterman}

(1984) kenyamanan diperngaruhi oleh jarak tempuh. Faktor yang mempengaruhi jarak tempuh adalah: (a) waktu yang berkaitan dengan maksud atau kepentingan berjalan kaki; (b) kenyamanan orang berjalan kaki dipengaruhi oleh cuaca dan jenis aktifitas.

\subsection{Karakteristik Pejalan Kaki}

Arus, adalah jumlah pejalan kaki yang melintasi suatu titik pada penggal ruang untuk pejalan kaki tertentu pada interval waktu tertentu dan diukur dalam satuan pejalan kaki per meter per menit:

$$
Q=\frac{N}{I^{*}}
$$

Dimana :

$\mathrm{Q}=$ arus pejalan $\mathrm{kaki},(\mathrm{org} / \mathrm{m} / \mathrm{mnt})$

$\mathrm{N}=$ jumlah pejalan kaki yang lewat (org/m)

$\mathrm{T}=$ waktu pengamatan (mnt)

Kecepatan adalah jarak yang dapat ditempuh oleh pejalan kaki pada suatu ruas trotoar per satuan waktu tertentu:

$V=\frac{L}{t}$

Dimana:

$\mathrm{V}=$ kecepatan pejalan kaki $(\mathrm{m} / \mathrm{mnt})$

$\mathrm{L}=$ panjang penggal pengamatan $(\mathrm{m})$

$\mathrm{T}=$ waktu tempuh pejalan kaki yang lewat segmen pengamatan

Ruang untuk pejalan kaki merupakan luas area rata-rata yang tersedia untuk masingmasing pejalan kaki yang dirumuskan dalam satuan m2/pejalan kaki. Ruang pejalan kaki adalah hasil dari kecepatan rata-rata ruang dibagi dengan arus, atau singkatnya ruang pejalan kaki adalah terbanding terbalik dengan kepadatan (Highway Capacity Manual, 2000):

$S=\frac{V S}{Q}=\frac{1}{D}$

Dimana:

$\mathrm{S}=$ Ruang pejalan kaki $\left(\mathrm{m}^{2} / \mathrm{org}\right)$

$\mathrm{D}=$ Kepadatan $\left(\mathrm{Org} / \mathrm{m}^{2}\right)$

$\mathrm{Q}=$ Arus (org $/ \mathrm{m} / \mathrm{mnt})$

Vs $=$ Kecepatan rata-rata ruang, $\left(\mathrm{m}^{2} / \mathrm{mnt}\right)$ 


\subsection{Tingkat Pelayanan Pejalan Kaki}

Kriteria yang digunakan sebagai syarat dalam menentukan tingkat pelayanan pada suatu ruang pejalan kaki dalam hal ini digunakan dua kriteria sebagai perbandingan yaitu:

Berdasarkan arus pejalan kaki (HCM, 2000):

$$
Q_{15}=\frac{N m}{15 W E}
$$

Dimana:

$\mathrm{Q}_{15}=$ arus pejalankaki pada interval 15 menitan terbesar (org/m/mnt)

$\mathrm{Nm}=$ Jumlah pejalan kaki terbanyak pada interval 15menitan (org)

$\mathrm{WE}=$ lebar efektif trotoar $(\mathrm{m})$

$\mathrm{WE}=\mathrm{WT}-\mathrm{B}$

Tabel 2.1. Tingkat Pelayanan Pejalan Kaki

\begin{tabular}{|c|c|c|c|c|}
\hline \multirow[b]{2}{*}{$\begin{array}{l}\text { Tingkat } \\
\text { Pelayanan }\end{array}$} & Space: & \multicolumn{3}{|c|}{ Arus dam Koccpalan yang Diharrapkam } \\
\hline & $\begin{array}{c}\mathrm{M}^{2} / \text { pejalan } \\
\text { kaji }\end{array}$ & $\begin{array}{c}\text { Kecepatan } \\
\text { mimini }\end{array}$ & $\begin{array}{c}\text { Volume } \\
\text { Anus } \\
\text { Pjlu } \\
\text { Kidkiminim }\end{array}$ & VoliCap \\
\hline A & -12 & -78 & $-6,5$ & -0.08 \\
\hline B & $=3.6$ & $=75$ & $=23$ & $=0.28$ \\
\hline C & 2.2 & 72 & 33 & 0.40 \\
\hline D & $=1.4$ & $=68$ & $=46$ & $=0.60$ \\
\hline L & 0.5 & 45 & 82 & 1.00 \\
\hline$F$ & $? 0.5$ & $? 15$ & Variabel & 1.00 \\
\hline
\end{tabular}

Sumber: Permen PU No. 03/PRT/M/2014

\section{METEDOLOGI PENELITIAN}

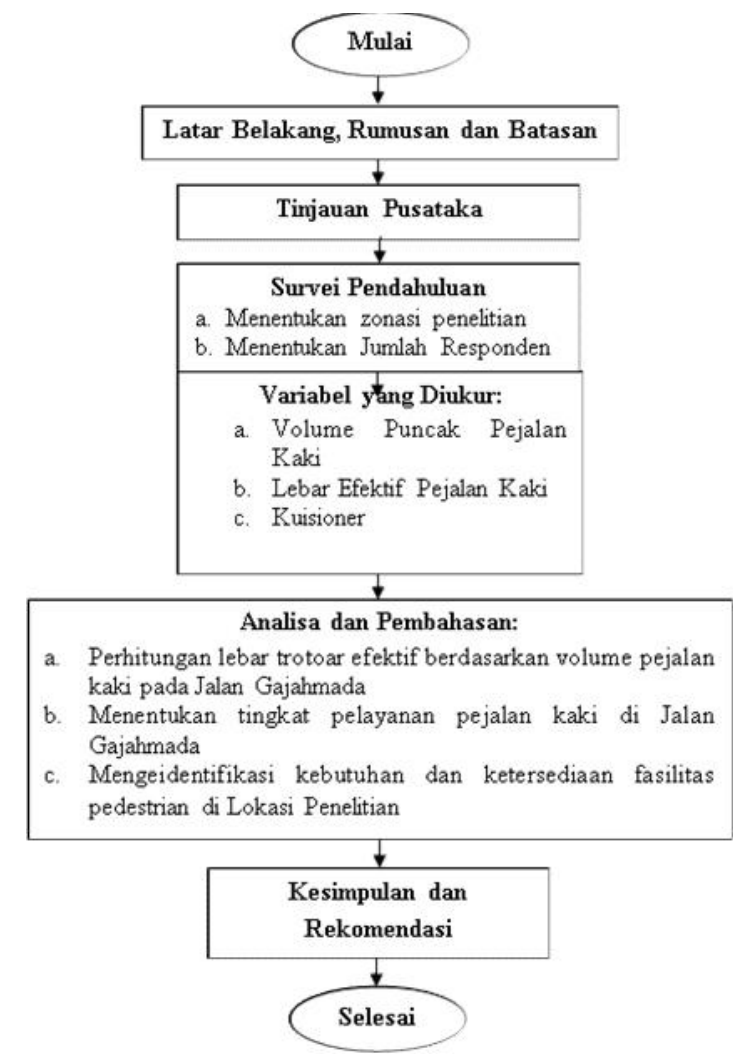

Gambar 3.1 Diagram Alir Penelitian 


\section{HASIL DAN PEMBAHASAN}

\subsection{Gambaran Umum Lokasi Penelitian}

Tabel 4.1. Data Geometrik Zonasi Penelitian

\begin{tabular}{|c|c|c|c|c|c|c|}
\hline No & Zouasi & Ruans & $\begin{array}{l}\begin{array}{l}\text { Paviange } \\
\text { (meter) }\end{array} \\
\end{array}$ & $\begin{array}{l}\text { Lebar } \\
\text { Efektif } \\
\text { (meter) }\end{array}$ & $\begin{array}{l}\text { Fasilitas } \\
\text { Difabel }\end{array}$ & $\begin{array}{c}\text { Marka } \\
\text { Penyebarangan }\end{array}$ \\
\hline 1 & I & $\begin{array}{l}\text { Jalan Letjen Suprapto } \\
\text { dan Restoran Mutiara }\end{array}$ & 144,23 & 10,68 & $\begin{array}{l}\text { Tidak } \\
\text { Ada }\end{array}$ & Tidak Ada \\
\hline 2 & II & $\begin{array}{l}\text { Jalan Hijas dan Hotel } \\
\text { Harnis Pontianak }\end{array}$ & 110,53 & 8,1 & $\begin{array}{l}\text { Tidak } \\
\text { Ada }\end{array}$ & Tidak Ada \\
\hline 3 & III & $\begin{array}{l}\text { Jalan Setia Budi dan } \\
\text { Hotel Gajahnada } \\
\text { Pontianak }\end{array}$ & 125,39 & 13,62 & $\begin{array}{l}\text { Tidak } \\
\text { Ada }\end{array}$ & Tidak Ada \\
\hline 4 & IV & $\begin{array}{l}\text { Jalam Siam dau Gg. } \\
\text { Gajahmada } 5\end{array}$ & 66,16 & 12,51 & Ada & Tidak Ada \\
\hline
\end{tabular}

4.2 Analisis Kebutuhan Lebar Jalur Pedestrian Zonasi

Berdasarkan hasil survey yang dilakukan pada lokasi penelitian zonasi I, total jumlah pejalan kaki sebanyak 344 orang. Jumlah pejalan kaki terbanyak ditunjukkan pada pukul 16.00 - 16.15 sebanyak 49 orang pejalan kaki dengan kecepatan rata-rata 11,17 detik.

Untuk mengetahui arus pejalan kaki, maka digunakan persamaan:

$$
v=\frac{V}{15 \cdot W_{\theta}}
$$

Keterangan:

$\mathrm{V}=$ Volume Puncak Pejalan Kaki (Org/15min)

$\operatorname{Kaki}(\mathrm{m})$

$$
\mathrm{W}_{\mathrm{e}}=\text { Lebar Efektif Jalur Pejalan }
$$

$$
v=\frac{49}{15 \cdot(10,68-2,0-4,0-0,7)}=0 \text {, }
$$

$\mathrm{V}=1 \mathrm{org} / \mathrm{menit} / \mathrm{meter}$

Berdasarkan hasil pengamatan di lapangan, lebar eksisting untuk zonasi 1 adalah 10,68 meter. Lebar tersebut dihitung dari rata-rata muka jalan ke muka bangunan gedung pada zonasi 1 . Namun lebar yang ada di lapangan tersebut, 10,68 meter tidak seluruhnya digunakan oleh pejalan kaki, karena sebagian besar telah digunakan tempat parkir kendaraan dan PKL. Lebar efektif yang ada pada zonasi 1 yaitu:

Dimensi trotoar

Lebar total $=10,68$ meter

Lebar reduksi parkir motor $=2,0$ meter

Lebar reduksi bangunan gedung $=$ 4,0 meter

Lebar reduksi $\mathrm{PKL}=0,7$ meter

Dari perhitungan diatas, didapatkan lebar efektif yang ada pada zonasi 1 belum sesuai dengan pedoman perencanaan.

Dalam merencanakan suatu kawasan perdagangan yang baik, maka diperlukan suatu jaringan penghubung berupa pedestrian yang baik, manusiawi dan bersahabat bagi pejalan kaki, tidak hanya pejalan kaki dengan kondisi normal, perencanaan juga harus mempertimbangkan kondisi pejalan kaki dengan kelemahan (Disabilities).

$$
\text { Berdasarkan Pedoman }
$$

Perencanaan, Penyediaan, dan Pemanfaatan Prasarana dan Sarana Jaringan Pejalan Kaki di Kawasan Perkotaan, untuk merencanakan kebutuhan lebar pedestrian berdasarkan kenyamanan pejalan kaki dan menyesuaikan dengan kondisi sekitar dan perlu ditambahkan lebar pedestrian untuk Pebih memperhatikan pejalan kaki dengan kelemahan (Disabilities), maka perlu penambahan pada jalur pedestrian untuk memperoleh lebar ideal trotoar bagi kawasan perdagangan dan jasa Jalan Gajahmada Pontianak: 


$$
W=\frac{V}{35}+N
$$

Keterangan:

$\mathrm{V}=$ Volume Pejalan Kaki

(Org/menit/meter)

$\mathrm{W}=$ Lebar Jalur Pedestrian

$\mathrm{N}=$ Lebar tambahan sesuai dengan keadaan setempat $(\mathrm{m})$

Jadi, $\mathrm{V}=1 \mathrm{org} / \mathrm{menit} /$ meter dan N

1,5 meter untuk lebar tambahan di kawasan perdagangan. Maka:

$$
\begin{aligned}
& W=\frac{1}{35}+\underset{\text { Lebar }}{1,5=1,53 \approx 2} \text { minimum untuk }
\end{aligned}
$$

kenyamanan pejalan kaki normal dengan volume pejalan kaki $1 \mathrm{org} / \mathrm{menit} / \mathrm{meter}$ adalah 2 meter.

Lebar minimum untuk pejalan kaki disabilitas yang menggunakan kursi roda dan tongkat adalah 1,2 m.

Lebar tambahan untuk elemen pendukung berupa pot bunga dan tempat duduk untuk penambah estetika adalah 1,5 meter. Maka, untuk mengetahui lebar ideal trotoar yang dibutuhkan dapat digunakan persamaan:

$\mathrm{LT}=\mathrm{L}_{\text {Normal }}+\mathrm{L}_{\text {Tambahan Pendukung }}$

$\mathrm{LT}=2 \mathrm{~m}+1,2 \mathrm{~m}+1,5 \mathrm{~m}$

$\mathrm{LT}=4,7 \mathrm{~m}$

Jadi, total lebar trotoar yang dibutuhkan untuk zonasi 1 adalah $4,7 \mathrm{~m}$ $\approx 5 \mathrm{~m}$.

Tabel 4.2. Hasil Rekapitulasi Kebutuhan

\begin{tabular}{||c|c|c|c|c|}
\multicolumn{5}{c|}{ Lebar Trotoar } \\
\hline No & Zonasi & \multicolumn{1}{|c|}{ Ruas } & $\begin{array}{l}\text { Arus Pejalan kaki } \\
\text { (Orgmnt/meter) }\end{array}$ & $\begin{array}{c}\text { Lebar Trotoar } \\
\text { (Meter) }\end{array}$ \\
\hline 1 & I & $\begin{array}{l}\text { Jalan Letjen Suprapto } \\
\text { dan Restoran Mutiara }\end{array}$ & 1 & 5 \\
\hline 2 & II & $\begin{array}{l}\text { Jalan Hijas dan Hotel } \\
\text { Harris Pontianak }\end{array}$ & 2 & 5 \\
\hline 3 & III & $\begin{array}{l}\text { Jalan Setia Budi dan } \\
\text { Hotel Gajahmada } \\
\text { Pontianak }\end{array}$ & 1 & 5 \\
\hline 4 & IV & $\begin{array}{l}\text { Jalan Siam dan Gg. } \\
\text { Gajahmada 5 }\end{array}$ & 2 & 5 \\
\hline
\end{tabular}

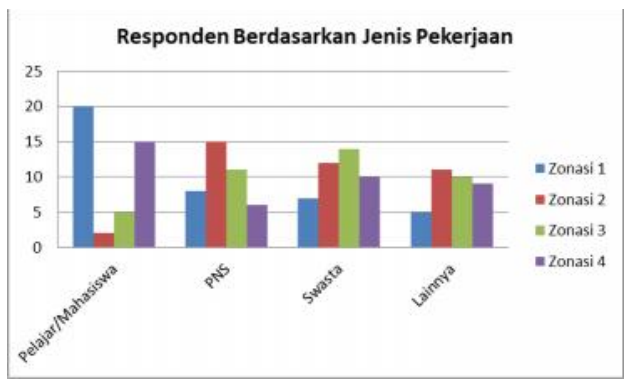

\subsection{Analisis Kebutuhan dan} Ketersediaan Fasilitas Pedestrian Pejalan kaki di Jalan Gajahmada Pontianak, menurut kategori sarana perjalanannya termasuk pejalan kaki pemakai kendaraan pribadi penuh, yaitu merupakan mereka yang menggunakan moda jalan kaki sebagai moda antara, dari tempat parkir kendaraan pribadi ke tempat tujuan akhir perjalanan.

Pejalan kaki di Jalan Gajahmada Pontianak, menurut kepentingan perjalanannya termasuk perjalanan fungsional, yaitu merupakan perjalanan untuk mencapai tujuan tertentu dari atau ke tempat kerja, sekolah, belanja dan lain-lain.

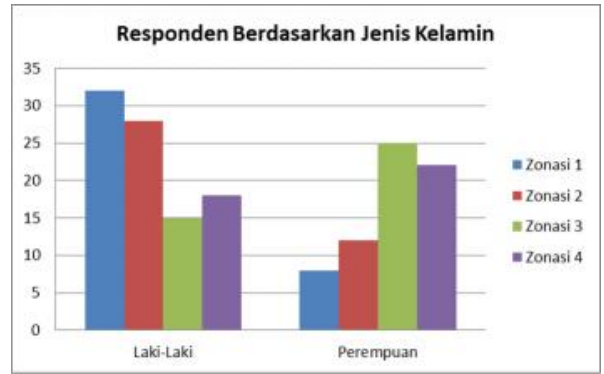

Gambar 4.1 Responden Berdasarkan Jenis Kelamin 
Gambar 4.2 Responden Berdasarkan Jenis Pekerjaan

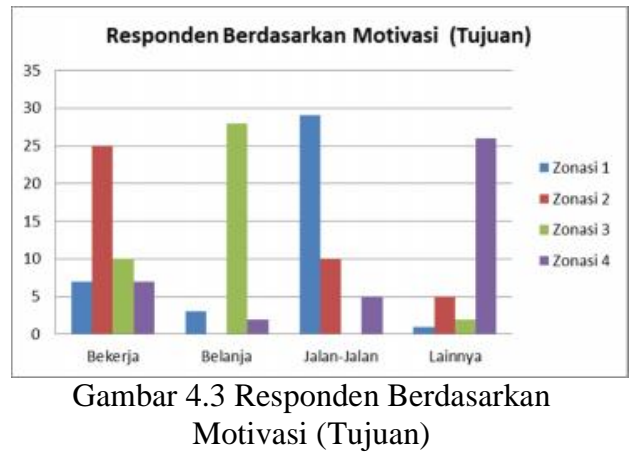

\subsection{Pembahasan Analisa Data}

Dari hasil analisa diatas, didapatkan bahwa zonasi-zonasi penelitian Jalan Gajahmada dapat direncanakan jalur pedestrian dengan lebar efektif 5 meter. Dengan perencanaan lebar 5 meter, Jalan Gajahmada dapat memiliki jalur pedestrian dengan tingkat pelayanan standar A.

Disamping itu, hasil responden menunjukkan karakteristik pejalan kaki di Jalan Gajahmada pada masing-masing zonasi tampak berbeda baik itu dilihat berdasarkan jenis kelamin, pekerjaan, tujuan, kebutuhan fasilitas.
Pertimbangan dalam perencanaan penyediaan prasarana dan sarana jaringan pejalan kaki menurut Pedoman Perencanaan, Penyediaan, dan Pemanfaatan Prasarana dan sarana Jaringan Pejalan Kaki di Kawasan Perkotaan untuk kawasan Perdagangan dan Jasa cocok untuk Jalan Gajahmada Pontianak yang telah ditetapkan dalam RTRW Kota Pontianak sebagai kawasan perdagangan dan jasa.

Menurut tipologi yang cocok di Kawasan Jalan Gajahmada, jalur pedestrian dengan tipologi covered walk (selasar) dikombinasikan dengan trotoar. Dimana fasilitas pedestrian dengan bentuk selasar dapat menghubungkan bagian bangunan yang satu dengan bangunan lainnya yang ada di Jalan Gajahmada. Sedangkan bentuk trotoar dapat direncanakan untuk fasilitas jalur pedestrian dengan lantai perkerasan yang terletak di kanan-kiri fasilitas jalan kendaraan bermotor.

Berikut Tabel 4.3 rencana dimensi jalur pedestrian di Jalan Gajahmada Pontianak, yaitu:

Tabel 4.3 Rencana Dimensi Jalur PedestrianDi Jalan Gajahmada Pontianak

\begin{tabular}{|c|l|c|}
\hline No & \multicolumn{1}{|c|}{ Uraian } & Dimensi (Meter) \\
\hline 1 & Lebar Jalan & 14,0 \\
\hline 2 & Lebar Median & 0,5 \\
\hline 3 & Lebar Trotoar Efektif & 5,0 \\
\hline 4 & Jalur Disabilitas (Kursi Roda) & 1,0 \\
\hline 5 & Jalur Hijau & 0,6 \\
\hline 6 & Tempat Duduk & 0,6 \\
\hline
\end{tabular}

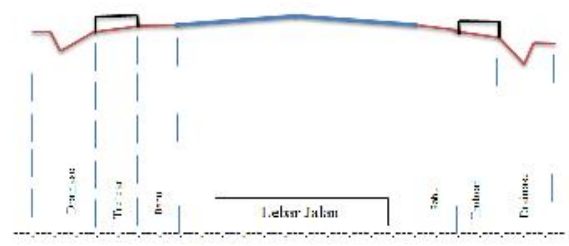


Gambar 4.4 Potongan Melintang Perencanaan Trotoar

\section{KESIMPULAN DAN SARAN}

5.1 Kesimpulan

1. Penelitian dilakukan dengan mengambil 4 titik zonasi yang menurut peneliti termasuk mempunyai aktivitas yang tinggi, yaitu:

a. Jalan Letjen Suprapto dan Restoran Mutiara

b. Jalan Hijas dan Hotel Harris Pontianak

c. Jalan Setia Budi dan Hotel Gajahmada Pontianak

d. Jalan Siam dan Gg. Gajahmada 5

2. Hasil perhitungan analisis kebutuhan lebar jalur pedestrian zonasi 1 didapatkan lebar efektif trotoar 5 meter. Dengan perhitungan yang didapatkan bahwa volume pejalan kaki pada zonasi 1 sebesar 1 org/menit/meter. Lebar minimum untuk kenyamanan pejalan kaki normal pada zonasi 1 yaitu sebesar 2 meter. Adanya lebar tambahan untuk mendukung elemen berupa jalur hijau, lampu penerangan dan tempat duduk sebagai penambah estetika.

3. Berdasarkan hasil analisis tingkat pelayanan fasilitas pejalan kaki, Jalan Gajahmada dapat direncanakan dengan tingkat pelayanan standar A atau LOS A.
4. Hasil analisis kebutuhan dan ketersediaan fasilitas pedestrian untuk Jalan Gajahmada berdasarkan hasil pengamatan kuisioner yang dilakukan di tiap-tiap zonasi.

5. Responden berdasarkan jenis kelamin laki-laki terbanyak ada di zonasi 1 dan jenis kelamin perempuan terbanyak ada di zonasi 3.

6. Responden berdasarkan jenis pekerjaan memiliki karakteristik yang berbeda-beda yaitu, pelajar/mahasiswa terbanyak ada di zonasi 1, pegawai negeri sipil terbanyak ada di zonasi 2 dan swasta terbanyak di zonasi 3.

7. Responden berdasarkan motivasi tujuan terbanyak adalah jalan-jalan pada zonasi 1 dan belanja pada zonasi 3.

8. Responden berdasarkan intensitas kunjungan terbanyak dilakukan respondedn yaitu selalu melewati jalan Gajahmada.

9. Responden berdasarkan waktu tempuh terbanyak membutuhkan waktu kurang dari 1 menit di 2 zonasi yaitu zonasi 1 dan zonasi 4 dikarenakan jarak dari pemberhentian kendaraan bermotor berjarak panjang daripada zonasi 2 dan zonasi 3.

10. Responden berdasarkan kebutuhan fasilitas pedestrian terbanyak memilih fasilitas tempat duduk, jalur hijau dan fasilitas penyebrangan.

11. Responden berdasarkan kebutuhan fasilitas mendukung moda transportasi menuju jalur pedestrian yaitu membutuhkan gedung parkir. 
12. Pembahasan analisa data direncanakan jalur pedestrian dengan lebar trotoar efektif 5 meter, jalur disabilitas (kursi roda) 1 meter, jalur hijau (pot bunga) 0,6 meter dan tempat duduk 0,6 meter.

\subsection{Saran}

a. Kawasan Jalan Gajahmada mempunyai karakteristik yang berbeda dibandingkan ruas jalan lainnya, hal ini dilihat dengan tingginya pertumbuhan ekonomi yang didapatkan oleh Pemerintah Kota Pontianak. Misalkan, pendapatan pajak hotel, aktivitas warung kopi, adanya toko swalayan dan toko-toko lainnya. Hal ini dapat dijadikan alasan untuk perencanaan jalur pedestrian agar para pengunjung Jalan Gajahmada lebih nyaman dan aman berada di Jalan Gajahmada.

b. Kondisi eksisting dan hasil analisa data, dapat dibuatkan perencanaan yang sesuai dengan yang disyaratkan. Dengan konsep beberapa zonasi jalur pedestrian digabung dan adanya gedung parkir yang tersedia di Jalan Gajahmada akan tetapi mengingat prilaku masyarakat Kota Pontianak yang tidak cukup senang dengan aktivitas berjalan kaki yang cukup jauh, peneliti menyarakan mengubah gedung parkir menjadi lahan kantong-kantong parkir dengan jarak jangkauan relatif dekat dengan tujuan agar tertata rapi dan tidak menganggu aktivitas pejalan kaki. c. Dikarenakan peneliti memiliki waktu yang terbatas, sebaiknya untuk penelitian selanjutnya lebih detail alam obeservasi lapangan agar mendapatkan data primer yang lebih valid.

\section{DAFTAR PUSTAKA}

Anggriani, Ninik., 2009. Pedestarian Ways Dalam Perencanaan Kota. Yayasan Humaniora.

Anonim. 2014. Peraturan Menteri Pekerjaan Umum Nomor: 03/PRT/M/2014 tentang Pedoman Perencanaan, Penyediaan, dan Pemanfaatan Prasarana dan Sarana Jaringan Pejalan Kaki di Kawasan Perkotaan. Jakarta. Menteri Pekerjaan Umum Republik Indonesia.

Anonim. 2013. Peraturan Daerah Kota Pontianak No. 7 Tahun 2012 tentang Rencana Tata Ruang Wilayah Kota Pontianak Tahun 2013-2033. Pontianak. Pemerintah Kota Pontianak.

Highway Capacity Manual. 2000. Pedestrian and Bicycle Concepts, American Association of State. Amerika Serikat

Indriastuti, A.K, Dkk. 2014. Evaluasi Kinerja Ruang Pejalan Kaki di Jalan Malioboro Yogyakarta. Jurnal. Semarang. Universitas Diponegoro

Kartika, Anak Agung Gede; Muhlas Hanik Wiganda,. 2012. Analisis Kinerja Jalur Pedestrian di Kota Surabaya (Studi Kasus: Jl. Pemuda). Teknik Sipil. Fakultas Teknik Sipil dan Perencanaan. Institut Teknologi Sepuluh November ( ITS ). Surabaya.

L. Mannering, Fred \& P. Kilareski, Walter. 1988. Principles of Highway Engineering and Traffic Analysis 4th Edition. Florida

Lulie (1995). Karakteristik dan Analisis Kebutuhan Fasilitas Pejalan Kaki Studi Kasus di Jalan Malioboro, Yogyakarta. Tesis. Bandung: Magister Teknik Sipil ITB. 
Prasetyaningsih, I. 2010. Analisis Karakteristik dan Tingkat Pelayanan Fasilitas Pejalan Kaki di Kawasan Pasar Malam Ngaarsopuro Surakarta. Skripsi. Surakarta. Universitas Sebelas Maret.

Sari, I. 2001. Analisa Pola Perjalanan Pejalan Kaki (Pedesterian) di Kawasan Pertokoan Dika dan Sekitarnya. Jurnal. Palembang. Universitas Sriwijaya

Uterman, Richard K. 1984. Acommodating The Pedestrian: Adapting Towns and Neighbohoods for Walking and Bicycling. New York.

Wibowo, L. 2005. Studi Tentang Kenyamanan Pejalan Kaki Terhadap Pemanfaatan Trotoar di Jalan Protokol Kota Semarang (studi Kasus Jalan MT. Haryoni Semarang). Jurnal. Semarang. Universitas Negeri Semarang.

Widodo, M. 2001. Jalur Pejalan Kaki Pandanaran Semarang. Tesis. Semarang. Universitas Diponegoro.

Yulianto, A. 2011. Pergerakan dan Fasilitas Pejalan Kaki di Kawasan Perkotaan Kabupaten Sumedang. Jurnal. Yogyakarta. Universitas Gajahmada.

Sudianto, B. U. 1997. Kebutuhan fasilitas pejalan kaki di pusat pertokoan: Studi kasus di pusat pertokoan Salatiga. Jurnal. Yogyakarta. Universitas Gajahmada. 